educational reformer Peter Ramus (1515-1572), the Dutch rationalist philosopher Baruch Spinoza (1632-1677) and the philosophers of the Enlightenment among the champions of the view that science provides an overarching measure of rationality and understanding. But scientism had its heyday with the movement known as logical positivism that developed with the Vienna Circle in the 1920s. Under similar influences Ludwig von Bertalanffy was promoting his General Systems Theory (GST) that sought to codify the processes underpinning nature, all the sciences, engineering, human organisation, economics and even design.

Because of their promise of providing instruments for making decisions and controlling organisations, such encyclopaedism, logical positivism, systems theory and the attendant optimistic scientism have been major influences in management, public administration and education. Scientism instils among many a sense of a plan and promises resolution in the event of a social crisis. With its pretence at rationality and externality, and rendering decision-making processes explicit that are otherwise hidden, it suggests public accountability.

The management scientist Herbert Simon was such an optimistic systematiser. He said in The Sciences of the Artificial in 1969: 'The professional schools will reassume their professional responsibilities just to the degree that they can discover a science of design, a body of intellectually tough, analytic, partly

formalisable, partly empirical, teachable doctrine about the design process. ${ }^{3}$

Early systems theory suggests that by logical rules, tables and charts, and that by laying complex issues out on a table or graph, one achieves a satisfactory overview. Everything is in its right box. There's also a bureaucratic strand to this latter-day Ramism: the bureaucratisation of knowledge, concepts illustrated in the checklists and self-evaluation tables that pervade research assessment in some quarters, and as illustrated well in van der Hoeven's article. This rationalist tendency is evident in the UK, as is the idea of assigning numbers and 'quality profiles' to performance in the REF.

But this positivist inclination is moderated in UK education and research fields by a pragmatic liberalism. The liberal influence of the American philosopher John Dewey is well-represented in the writings of theorists of education, organisation, urban studies and design Chris Argyris and Donald Schön, who offer polite riposte to Simon's systematisation, highlighting the complex interplay of problem setting, reflection, action, interpretation and metaphor within professional life and human rationality.

Research in the UK seems to be characterised by a pluralism so informed. In some quarters, there is recognition that there are many research paradigms, models and views in play which are often critical of one another. The differences are for peer review groups to resolve or accommodate. Public accountability is important, and even social, cultural and economic impact, but these do not require putative scientific methods for their assessment, or the requirement that all researchers see their work as science.

In the United Kingdom, there are eight major governmentsponsored research funding councils supporting science, medicine, engineering and the social sciences. The most recently formed funding body is the Arts and Humanities Research Council (AHRC) that explicitly encourages, and funds, art and design practice as modes of research, and creative works, exhibitions, designs, buildings, compositions and performances as research output. In its documentation and practice, this research council seems genuinely led by a desire to assert subject matter, approaches and methods that come from within the arts and humanities, without needing to draw on the authority and techniques of science. This liberal approach seems currently to be mirrored in the REF.

There are threats to the arts and humanities. The UK government intends to drop central funding for non-STEM subjects in Universities (ie subjects outside of science, technology, engineering and mathematics) with the shortfall to be met by student fees. But whatever this means for the arts and humanities, it does not suggest, or require, the re-introduction of a new bureaucratic scientism to research policy in the country.

Architectural practice has long decided that there was no need to appeal to science to legitimate its activities, and the studio teaching method, with its open-ended, dialogical and materially-based practices, has reasserted itself as a highly respected model of education, and of research. Doubtless there are battles to be waged in the UK HE sector, but not against science.

RICHARD COYNE Edinburgh

Richard Coyne is Professor of Architectural Computing at the University of Edinburgh and was formerly Head of the School of Arts, Culture and Environment. He authored Derrida for Architects (Routledge, 2011) and co-authored Interpretation in Architecture: Design as a Way of Thinking with Adrian Snodgrass (Routledge, 2006).

\section{Subject and object}

As a member of the original Editorial Board of arq, I am prompted by the receipt of the latest issue, Volume 15, Issue 1, to write and congratulate the present Editors and Board on the consistently high standard of the journal. It now more than fulfils the aspirations of its founders in providing a world-class platform for the publication of architectural research from both academia and practice. It is a pleasure to see the quality, diversity and global origins of the papers that are now published.

Over 40 years ago I had the privilege to be one of the founder members of what is now the Martin Centre for Architectural and Urban Studies at Cambridge and it was a particular pleasure to read Charles Rattray's and Ivor Richards' account of their conversation with Trevor Dannatt in the latest issue, 'Subject and object'. This provided a reminder of the essential parallels between practice and research in the work of many of those who worked with Leslie Martin at the L.C.C., and in the Cambridge years in both the school of architecture and the studio. It was particularly valuable to read Trevor's recollections of his relationship with Martin - the reference to an interview that became a seminar will be familiar to many.

I hope I may be allowed a personal response to the description and images of Trevor's Pitcorthie House, built in 1966. I am intrigued by the similarities between Trevor's design and that of a small house that I built a quarter of a century later in Cambridge. ${ }^{4}$ Although, at the time, I was unaware of the earlier house, the Cambridge design has a similar, south-facing glazed gallery that links the living room with the 


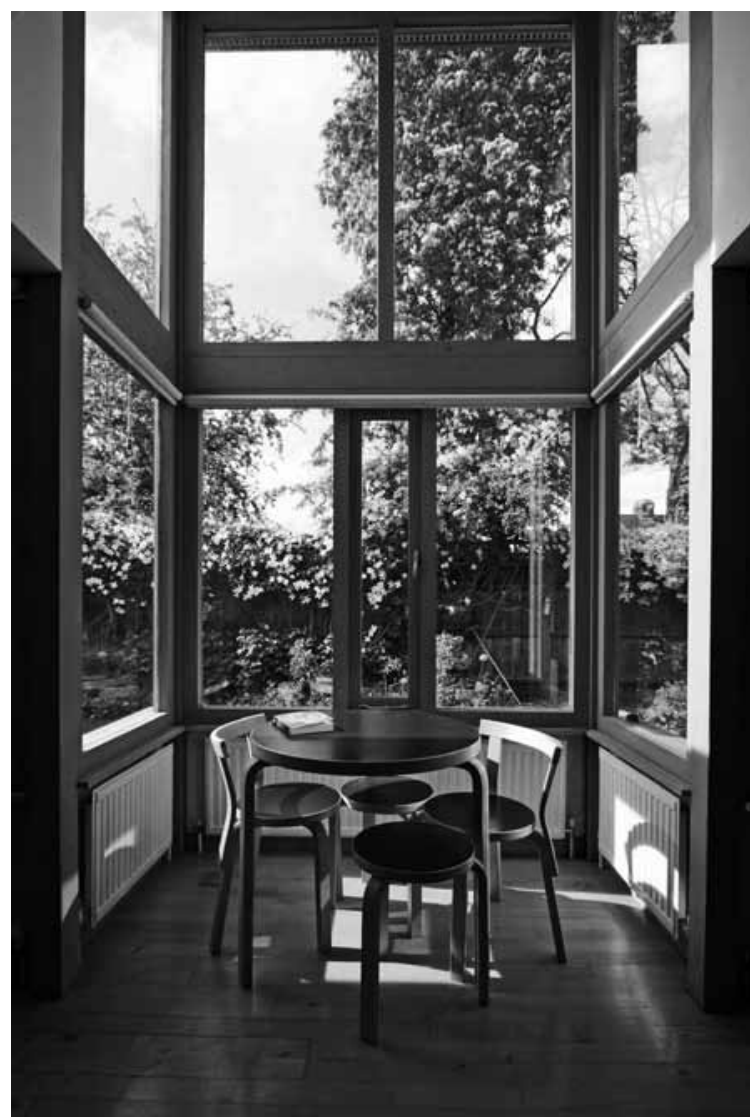

1 Hawkes House, Cambridge. A bay window is part of the south-facing glazed gallery.

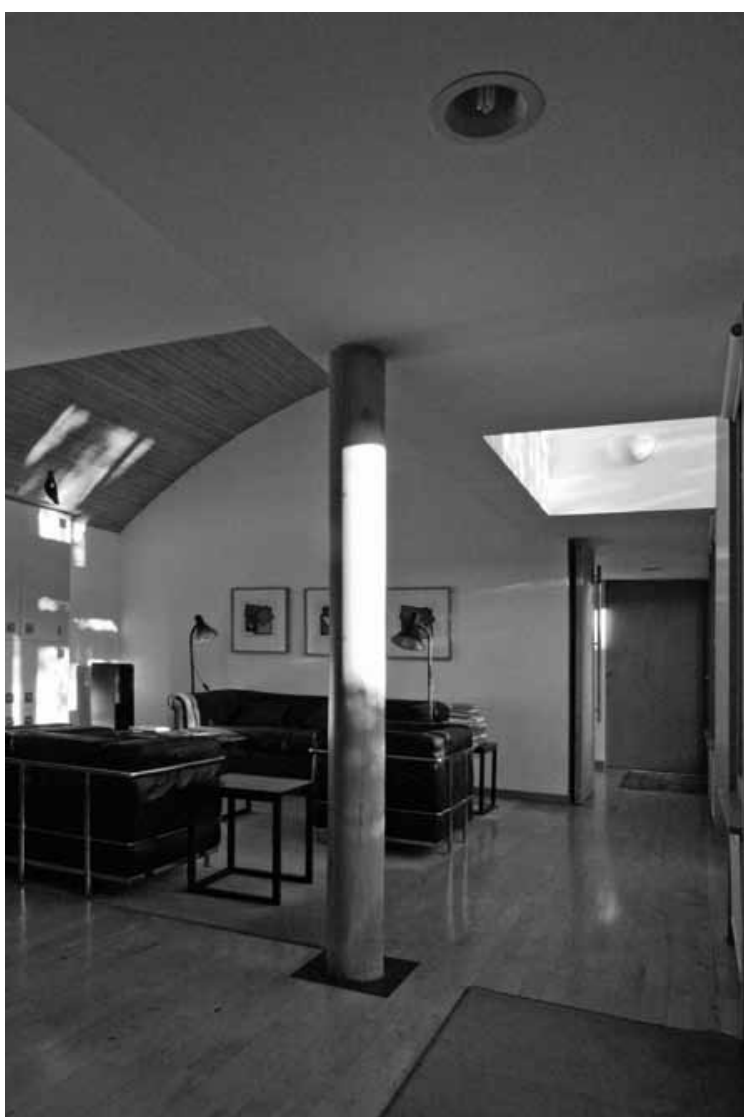

2 Hawkes House, Cambridge. A column articulates the spatial order of the living room. The dividing door with the bedroom is set on a floor pivot. principal bedroom, although here the dividing door, which is rarely closed, is on a floor pivot, rather than retracting into the dividing wall. Perhaps more striking is the use of a single column to articulate the spatial order of the living room in each house.

I am reluctant to develop a complex argument for these coincidences - in fact I think I prefer affinities. I would, however, like to suggest that they have their roots in a shared architectural culture in which designs are founded upon careful and humane responses to programme and context realised through the use of primarily straightforward construction. The approach is eloquently captured in Trevor Dannatt's distinction between the subject and object in the title of this memorable conversation.

\section{DEAN HAWKES} Cambridge

Dean Hawkes is emeritus Professor of Architectural Design at the Welsh School of Architecture, Cardiff University and emeritus fellow of Darwin College, University of Cambridge. He was Director of the Martin Centre for Architectural and Urban Studies at Cambridge, 1979-1987

\section{Notes}

1. HEFCE, REF2014: Assessment Framework and Guidance on Submissions (Bristol: Higher Education Funding Council for England, 2011).

2. Alan F. Chalmers, What is This Thing Called Science? (Indianapolis, IN: Hackett, 1999), p. 1.

3. Herbert Simon, The Sciences of the Artificial (Cambridge MA: MIT Press, 1969), p. 58.

4. See: Marcus Field, 'Building Study: House at Cambridge', The Architects' Journal, 7 March 1996, pp. 37-41, and Dean Hawkes, 'Critical Practice: The Architectural Environment', in Nicholas Temple and Soumyen Bandyopadhyay (eds), Thinking Practice: Reflections on Architectural Research and Building Work (London: Black Dog, 2007).

\section{Illustration credits:}

arq gratefully acknowledges:

Dean Hawkes, all images

Letters for publication should be sent to:

Adam Sharr

adam.sharr@newcastle.ac.uk

The Editors reserve the right to shorten letters

\section{Erratum}

An error in arq 15.2 has been brought to the editor's attention, for which we wish to apologise. In Downward Trajectory: Towards a Theory of Failure by Timothy Brittain-Catlin the email in the author's address should have been T.J.Brittain-Catlin@kent.ac.uk.

We regret any confusion this error may have caused. 